\title{
Integrated use of technogenic raw materials in cement technology
}

\author{
L.P. Chernyak (ORCID 000-0001-8479-0545), L.I. Melnyk (ORCID 0000-0001-5139-3105), \\ N.O. Dorogan (ORCID 0000-0002-4304-1297), I.A. Goloukh
}

National Technical University of Ukraine "Igor Sikorsky Kyiv Polytechnic Institute”, av. Peremogy, 37, Bldg. 21, Kyiv, 03056, Ukraine

Tel.: +380672985775, +380634212-97, +380987143039, +380664424116

E-mail: lpchernyak@ukr.net,luba_xtkm@ukr.net,nataliyadorogan@ukr.net,ira.golojuch@gmail.com

Article info: received 10.05.2021, revised 26.05.2021, accepted 23.06.2021

Chernyak, L.P., Melnyk, L.I., Dorogan, N.O., Goloukh, I.A. (2021) Integrated use of technogenic raw materials in cement technology 2(51), DOI: 10.26909/csl.2.2021.3

This work used a combination of modern physico-chemical research methods with standardized testing of technological and operational properties of raw materials, clinker, cement and compositions with its application.

Results over of research of the silicate systems with rice husk and ash-fly as technogenic raw material for making of cement clinker are driven. The features of the chemical-mineralogical composition, phase transformations during burning and astringent properties of material at the use of 42,5 - 50,5\% industry wastes in composition initial raw material mixtures are shown.

The object of the study were raw material mixtures for the production of Portland cement clinker based on the systems of chalk - clay - man-made raw materials and chalk - man-made raw materials.

The possibility of replacing exhaustible and non-renewable natural raw materials with a complex of multi-tonnage wastes of agro-industry and heat energy, which meets the objectives of expanding the raw material base of cement production, resource conservation and environmental protection.

Peculiarities of phase formation during firing of silicate systems of chalk-polymineral clay and chalk-technogenic raw materials taking into account changes in the quantitative ratio of components, in particular rice husk and ash-removal of thermal power plants are noted.

Key words: raw materials, cement clinker, chemical-mineralogical composition.

\section{Комплексне використання техногенної сировини в технології цементу}

\author{
Л.П. Черняк, Л.І. Мельник, Н.О. Дорогань, І.А. Голоюх \\ Національний технічний університет Украӥни “Київський політехнічний інститут”, \\ Київ, Украӥна
}

Наведені результати досліджень силікатних систем із комплексним використанням рисової лузги та золи-виносу ТЕС як техногенної сировини для виготовлення цементного клінкеру. Показано особливості хіміко-мінералогічного складу, фазових перетворень при випалі та в’яжучих властивостей матеріалу при використанні 42,5 - 50,5 мас. \% відходів промисловості в складі вихідних сировинних сумішей.

\section{Вступ}

Збільшення обсягів практичного використання багатотоннажних відходів промисловості відповідає комплексному вирішенню задач екології, ресурсозбереження та розвитку силікатних виробництв [1 - 6]. Разом з тим, більшість відомих розробок щодо утилізації відходів промисловості в виробництві силікатних матеріалів спрямовані на їх використанні як добавки до сировинних складів діючих технологічних процесів, не розглядаючи можливість збільшення об' єму утилізації шляхом створення та використання нових складів.

Серед багатотоннажних відходів вагоме місце займають золи-виноси ТЕС і рисова лузга [7, 8], що утворюється у агропромисловому комплексі. За хіміко-мінералогічним складом ці відходи можуть розглядатися як компонент в технології силікатів, в 
тому числі в’яжучих матеріалів. Проте обсяги практичного використання вказаних відходів не відповідають обсягам їх утворення і накопичення.

Мета дослідження. В напрямку розв'язання задачі збільшення обсягів ефективної утилізації відходів промисловості як техногенної сировини в виробництві в'яжучих матеріалів виконана дана робота.

\section{Матеріали та методи дослідження}

В роботі використовувалось поєднання сучасних фізико-хімічних методів дослідження із стандартизованими тестуваннями технологічних і експлуатаційних властивостей сировинних матеріалів, клінкеру, цементу та композицій з його застосуванням $[9,10]$.

Визначення хімічного складу проб сировини проводились згідно ДСТУ Б В.2.7-202:2009, що поширюється на сировинні суміші, мінеральні добавки, сировину, клінкер та цемент, які застосовують у цементному виробництві.

Рентгенофазовий аналіз порошкового препарату проводили за допомогою дифрактометру ДРОН-3М (випромінювання $\mathrm{Cu} \mathrm{K \alpha} 1-2$, напруга 40 кB, струм 20 мА, швидкість 2 град/хв.).

Відповідно до сучасної технології в'яжучих сировинні суміші визначеного складу готували шляхом дозування компонентів по масі, змішування та гомогенізації при помелу у кульовому млині, випалу і помелу кінцевого продукту.

Всі зразки дослідних сумішей, показники яких порівнювали, сушили та випалювали разом, аби виключити можливість різниці в ступені термічної обробки.

Об'єктом дослідження стали сировинні суміші для виготовлення портландцементного клінкеру на основі систем крейда - глина - техногенна сировина та крейда - техногенна сировина.

\section{Результати та їх обговорення}

Проби вихідної сировини за хімічним складом (табл. 1) відрізняються кількісним вмістом оксидів, утворюючи наступні ряди, мас. \%:

- по $\mathrm{SiO}_{2}$ : крейда < лузга < зола-виносу < глина;

- по $\mathrm{Al}_{2} \mathrm{O}_{3}$ : зола-виносу > глина > крейда і лузга;

- по СaO: крейда > зола-виносу > глина > лузга;

- по $\mathrm{Fe}_{2} \mathrm{O}_{3}$ : зола-виносу $>$ глина $>$ крейда і лузга;

- по $\mathrm{Na}_{2} \mathrm{O}+\mathrm{K}_{2} \mathrm{O}$ : глина > зола-виносу > лузга.

Основним породоутворюючим мінералом рисової лузги $є$ аморфний кремнезем, зола-виносу відзначається наявністю склофази та кристалічних фаз, головним чином - кварцу, муліту (рис. 1, 2).

Очевидно, що у досліджуваних силікатних системах для виготовлення цементного клінкеру глина, зола-виносу та лузга слугуватимуть джерелом $\mathrm{SiO}_{2}$, необхідного для утворення при випалі основних клінкерних мінералів, проте різного ступеню кристалічності та, відповідно - реакційної здатності: 3 глиною та золою-виносу у систему вводиться кристалічний $\beta$-кварц, а з лузгою - аморфний кремнезем.

Розрахунки та аналіз складу сировинних сумішей для виготовлення цементного клінкеру проводили 3 використанням комп'ютерної програми «КЛІНКЕР» згідно відомих рекомендацій відносно числових значень коефіцієнту насичення КН, кремнеземного n та глиноземного р модулів $[11,12]$.

Аналіз отриманих результатів показав, що у рекомендованому інтервалі КН можлива концентрація відходів переробки рису у складі сировинних сумішей суттєво залежить від різновидів та кількісного співвідношення інших компонентів. При цьому між вмістом відходів та значенням коефіцієнту насичення існує обернено пропорційна залежність. (рис. 3).

Так, у трьохкомпонентній суміші на основі системи крейда - глина кривинська - рисова лузга можливий вміст останнього становить від 5,6 до 18,4 мас. \%, а на основі системи крейда - зола ви-

Таблиця 1.

Хімічний склад сировини

\begin{tabular}{|l|c|c|c|c|c|c|c|c|c|c|}
\hline \multirow{2}{*}{ Назва проби } & \multicolumn{70}{|c|}{ Вміст оксидів, мас. \% } \\
\cline { 2 - 13 } & $\mathrm{SiO}_{2}$ & $\mathrm{Al}_{2} \mathrm{O}_{3}$ & $\mathrm{Fe}_{2} \mathrm{O}_{3}$ & $\mathrm{TiO}_{2}$ & $\mathrm{CaO}$ & $\mathrm{MgO}$ & $\mathrm{SO}_{3}$ & $\mathrm{Na}_{2} \mathrm{O}$ & $\mathrm{K}_{2} \mathrm{O}$ & \multirow{2}{*}{ в.п.п } \\
\hline Крейда & 0,77 & 0,25 & 0,13 & - & 55,0 & 0,25 & 0,08 & - & - & 43,49 \\
\hline Глина & 60,96 & 15,66 & 5,57 & 0,79 & 3,33 & 2,04 & 0,16 & 0,30 & 2,70 & 8,48 \\
\hline Зола-виносу & 46,12 & 18,00 & 22,17 & 1,78 & 4,03 & 1,46 & 0,21 & - & 2,10 & 1,49 \\
\hline Лузга & 15,64 & 0,24 & 0,12 & - & 0,61 & 0,45 & 0,18 & 0,48 & 0,28 & 82 \\
\hline
\end{tabular}




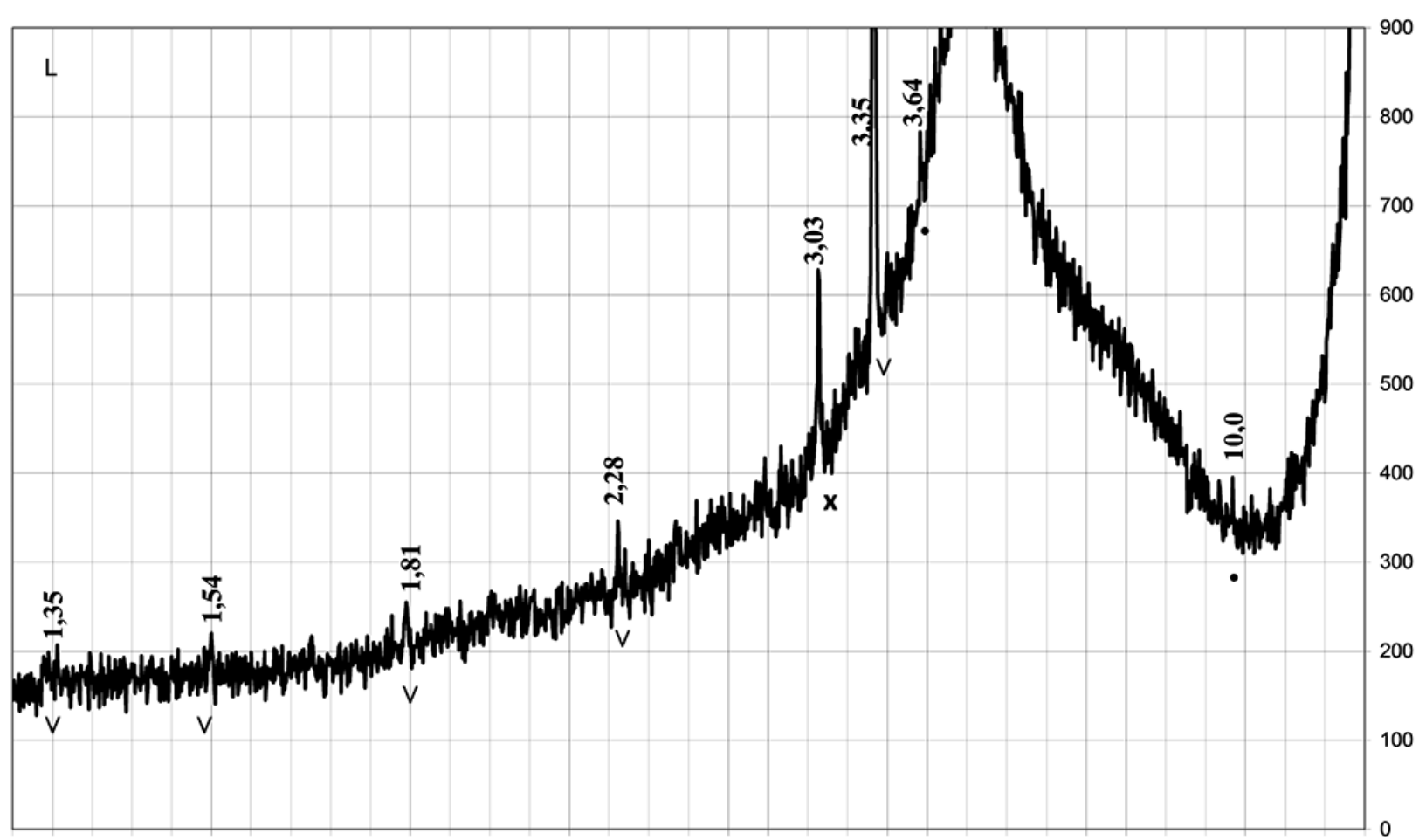

$\begin{array}{lllllllllllllllllllllllllllllllllll}70 & 68 & 66 & 64 & 62 & 60 & 58 & 56 & 54 & 52 & 50 & 48 & 46 & 44 & 42 & 40 & 38 & 36 & 34 & 32 & 30 & 28 & 26 & 24 & 22 & 20 & 18 & 16 & 14 & 12 & 10 & 8 & 6 & 4 & 2\end{array}$

Рис. 1. Дифрактограма проби рисової лузги.

Позначення: v - кварц; х - кальцит

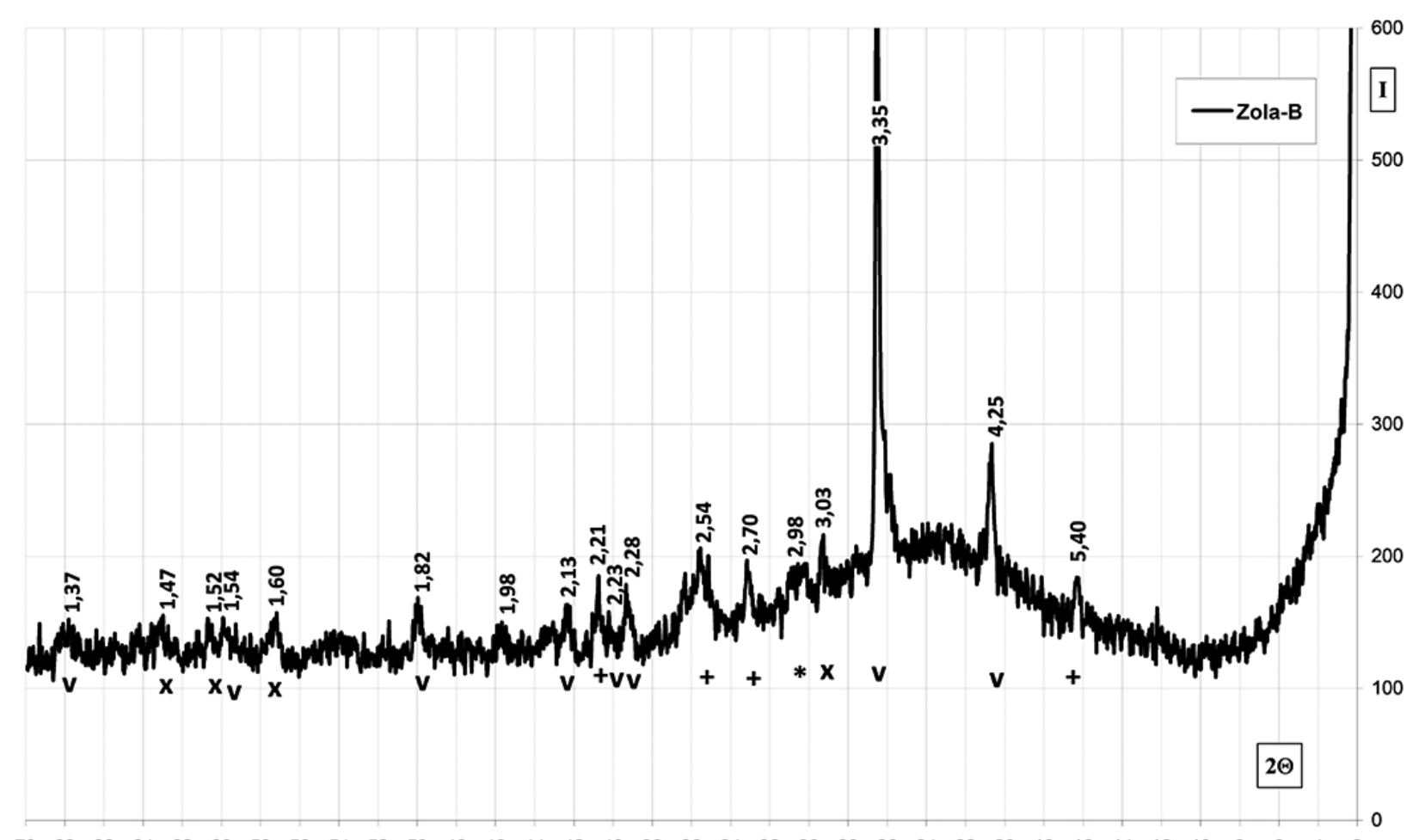

$\begin{array}{lllllllllllllllllllllllllllllllllllll}70 & 68 & 66 & 64 & 62 & 60 & 58 & 56 & 54 & 52 & 50 & 48 & 46 & 44 & 42 & 40 & 38 & 36 & 34 & 32 & 30 & 28 & 26 & 24 & 22 & 20 & 18 & 16 & 14 & 12 & 10 & 8 & 6 & 4 & 2\end{array}$

Рис. 2. Дифрактограма золи-виносу.

Позначення: v - кварц; + - муліт; х - кальцит 

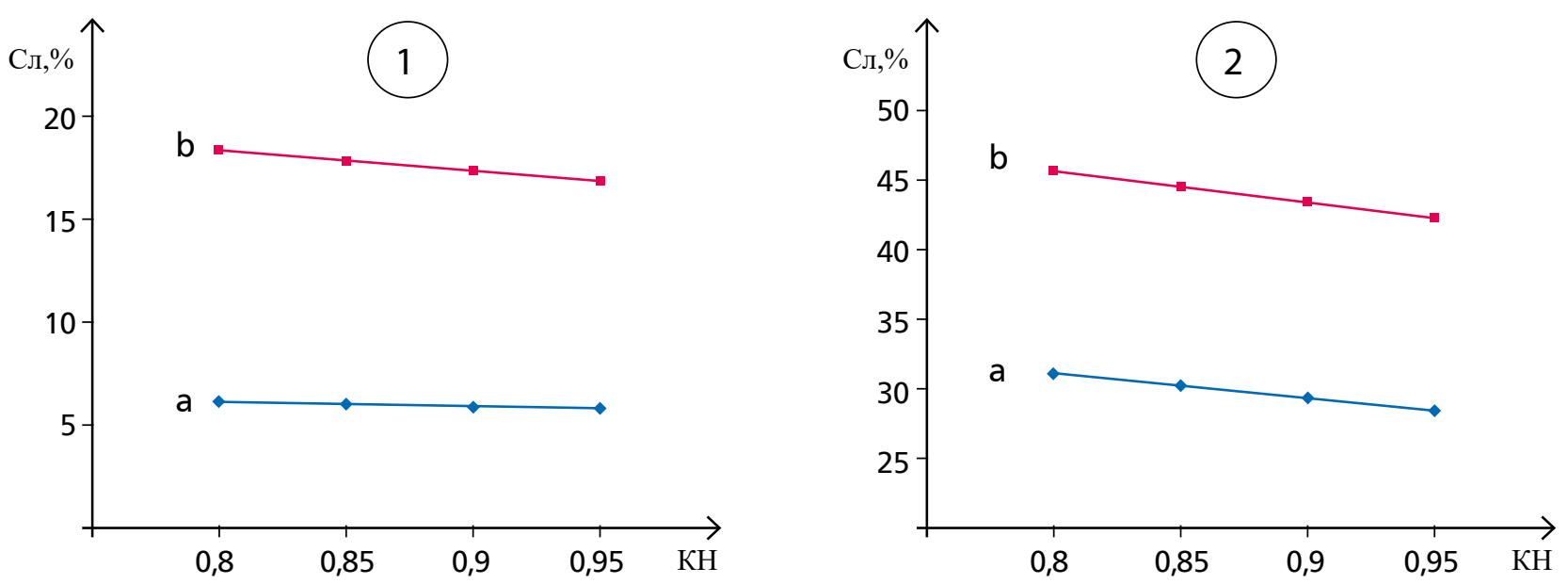

Рис. 3. Залежність вмісту лузги (Сл) в суміші на основі систем крейда - глина кривинська (1) і крейда - зола-виносу (2) від коефіцієнту насичення КН клінкеру при кремнеземному модулі $\mathrm{n}=3,0$ (a) i $\mathrm{n}=3,5$ (b)

носу - рисова лузга можливий вміст останнього становить від 28,4 до 45,8 мас. \%. При цьому в обох системах має місце зворотно пропорційна залежність концентрації лузги від значення.

На основі проведених розрахунків та відповідно до мети даної роботи для дослідження було обрано склади сировинних сумішей з можливим сумарним вмістом 42,5 - 50,5 мас. \% відходів промисловості (10L, 11L) при порівнянні 3 відомим виробничим складом Вк (табл. 2).
Аналіз хімічного складу досліджуваних сумішей свідчить, що застосування техногенної сировини замість полімінеральної глини призводить до збільшення кількісного співвідношення $\mathrm{SiO}_{2}: \mathrm{Al}_{2} \mathrm{O}_{3}$ від 3,6 до 4,4 - 7,4, $\mathrm{CaO}: \mathrm{Al}_{2} \mathrm{O}_{3}$ від 11,0 до 12,4 - 19,6 при зменшенні співвідношення $\mathrm{CaO}: \mathrm{SiO}_{2}$ з 3,1 до 2,8 - 1,7 та вмісту $\mathrm{MgO}$ (табл. 3.). Вказані відмінності найбільше проявляться у випадку проби $11 \mathrm{~L}$ при співвідношенні концентрацій лузги з золою-виносу 7,4 .

Таблиця 2.

Склад сумішей для виготовлення клінкеру

\begin{tabular}{|l|c|c|c|c|c|}
\hline \multirow{2}{*}{ Код суміші } & \multicolumn{5}{|c|}{ Вміст компонентів, мас. \% } \\
\cline { 2 - 6 } & Крейда & Глина кривинська & Рисова лузга & Зола виносу & Червоний шлам \\
\hline Вк & 77,2 & 21,1 & - & - & 1,7 \\
\hline $10 \mathrm{~L}$ & 57,5 & - & 30,0 & 12,5 & - \\
\hline $11 \mathrm{~L}$ & 49,5 & - & 44,5 & 6,0 & - \\
\hline
\end{tabular}

Таблиця 3.

Хімічний склад сировинних сумішей

\begin{tabular}{|l|c|c|c|c|c|c|c|}
\hline \multirow{2}{*}{ Код проби } & \multicolumn{9}{|c|}{ Вміст оксидів, мас.\% } \\
\cline { 2 - 9 } & $\mathrm{SiO}_{2}$ & $\mathrm{Al}_{2} \mathrm{O}_{3}$ & $\mathrm{Fe}_{2} \mathrm{O}_{3}$ & $\mathrm{CaO}$ & $\mathrm{MgO}$ & $\mathrm{SO}_{3}$ & в. п. п \\
\hline $\mathrm{B \kappa}$ & 14,14 & 3,93 & 2,21 & 43,32 & 0,64 & 0,10 & 35,66 \\
\hline $10 \mathrm{~L}$ & 11,32 & 2,60 & 3,05 & 32,32 & 0,47 & 0,13 & 50,11 \\
\hline $11 \mathrm{~L}$ & 10,42 & 1,41 & 1,56 & 27,68 & 0,42 & 0,13 & 58,38 \\
\hline
\end{tabular}


Зміни хімічного складу клінкеру відповідають вказаному складу вихідних сировинних сумішей та обумовлюють характеристики та фазовий склад матеріалу після випалу (табл. 4, 5).

Так, за розрахунками по формулам професора В.А. Кинда згідно діючого стандарту $[13,14]$ прогнозний фазовий склад проб 10L, 11L відрізняється від проби Вк більшим утворенням кристалічних фаз алю- мінатів кальцію типу $\mathrm{C}_{3} \mathrm{~A}$ (29,3 - 32,3 проти 16,3 \%), зменшенням утворень $\mathrm{C}_{3} \mathrm{~S}(47,4$ - 52,3 проти 58,2 \%) та $\mathrm{C}_{3} \mathrm{~A}(2,6$ - 3,4 проти 14,3\%). У випадку проби 10L прогнозується збільшення вмісту кристалічної фази $\mathrm{C}_{4} \mathrm{AF}$ (рис. 4).

Отримані результати технологічних тестувань свідчать, що використання сировинних сумішей 3 комплексним застосуванням рисової лузги та зо-
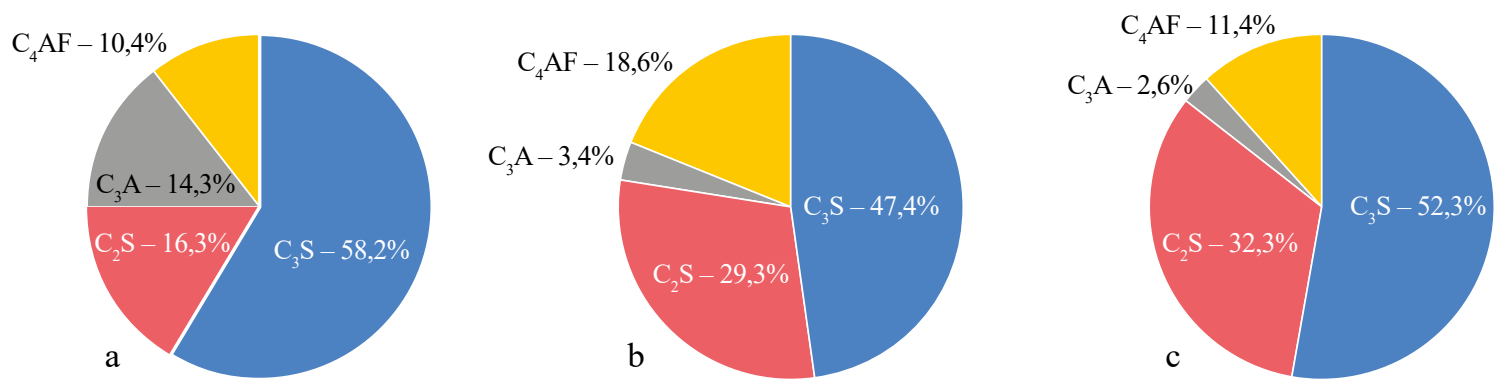

Рис. 4. Співвідношення кристалічних фаз у досліджуваному клінкері Bк (a), 10L (b), 11L (c)

Таблиця 4.

Хімічний склад клінкеру

\begin{tabular}{|l|c|c|c|c|c|c|}
\hline \multirow{2}{*}{ Код проби } & \multicolumn{7}{|c|}{ Вміст оксидів, мас.\% } \\
\cline { 2 - 8 } & $\mathrm{SiO}_{2}$ & $\mathrm{Al}_{2} \mathrm{O}_{3}$ & $\mathrm{Fe}_{2} \mathrm{O}_{3}$ & $\mathrm{CaO}$ & $\mathrm{MgO}$ & $\mathrm{SO}_{3}$ \\
\hline $\mathrm{B \kappa}$ & 21,98 & 6,11 & 3,43 & 67,33 & 0,99 & 0,16 \\
\hline $10 \mathrm{~L}$ & 22,69 & 5,21 & 6,11 & 64,79 & 0,94 & 0,26 \\
\hline $11 \mathrm{~L}$ & 25,04 & 3,38 & 3,75 & 66,51 & 1,01 & 0,31 \\
\hline
\end{tabular}

Таблиця 5.

Розрахункові характеристики клінкеру

\begin{tabular}{|l|c|c|c|c|c|c|c|}
\hline \multirow{2}{*}{ Код проби } & \multicolumn{3}{|c|}{ Характеристики клінкеру } & \multicolumn{4}{|c|}{ Вміст $\mathrm{C}_{2} \mathrm{~S}$ кристалічних фаз, \% } \\
\cline { 2 - 9 } & $\mathrm{KH}$ & $\mathrm{n}$ & $\mathrm{p}$ & $\mathrm{C}_{3} \mathrm{~S}$ & $\mathrm{C}_{2} \mathrm{~S}$ & $\mathrm{C}_{3} \mathrm{~A}$ & $\mathrm{C}_{4} \mathrm{AF}$ \\
\hline $\mathrm{B \kappa}$ & 0,91 & 2,30 & 1,78 & 58,2 & 16,3 & 14,3 & 10,4 \\
\hline $10 \mathrm{~L}$ & 0,85 & 2,00 & 0,85 & 47,42 & 29,27 & 3,44 & 18,57 \\
\hline $11 \mathrm{~L}$ & 0,85 & 3,51 & 0,90 & 52,33 & 32,30 & 2,60 & 11,40 \\
\hline
\end{tabular}

Таблиця 6.

Властивості в’яжучого матеріалу

\begin{tabular}{|c|c|c|c|c|}
\hline \multirow{2}{*}{\multicolumn{2}{|c|}{ Показники }} & \multicolumn{3}{|c|}{ Код проби } \\
\hline & & Вк & $10 \mathrm{~L}$ & $11 \mathrm{~L}$ \\
\hline \multicolumn{2}{|c|}{ Тонкість помелу, залишок на ситі 008, мас. \% } & 13 & 13 & 13 \\
\hline \multirow{2}{*}{ Терміни тужавлення, хв. } & початок & 30 & 25 & 40 \\
\hline & кінець & 115 & 110 & 130 \\
\hline \multicolumn{2}{|c|}{ Міцність на стиск через 28 діб, МПа } & 38,0 & 36,5 & 38,5 \\
\hline
\end{tabular}


ли-виносу забезпечує виготовлення цементу з показниками тужавлення та міцності, аналогічними відомому виробничому складу Вк (табл. 6).

\section{Висновки}

1. Встановлена можливість заміни вичерпної та невідновлюваної природної сировини комплексом багатотоннажних відходів агропромисловості та теплоенергетики, що відповідає задачам розширення сировинної бази виробництва цементу, ресурсозбереження та охорони довкілля.

2. Відзначено особливості фазоутворення при випалі силікатних систем крейда-полімінеральна глина та крейда-техногенна сировина з урахуванням змін кількісного співвідношення компонентів, зокрема рисової лузги та золи-виносу ТЕС.

\section{References}

1. Удачкин, И.Б., Пащзенко, А.А., Черняк, Л.П. и др. Комплексное развитие сырьевой базы промышленности строительных материалов. - К.: Будівельник.1988. - 104 c.

2. Пащченко, А.А., Мясникова, Е.А., Евсютин, Е.Р. Энергосберегающие и безотходные технологии получения вяжущих веществ. - К.: Вища школа. 1990. - 223 c.

3. Дворкин, Л.И., Дворкин, О.Л. Строительные материалы из отходов промышленности: учебно-справочное пособие. - Ростов н/Д: Феникс. 2007. -363 c.

4. Моссур, П.М., Негода, С.В. Техногенное минеральное сырье и его использование в Украине ГИАБ. - 2007. - № 6. - С. 299 - 307.
5. Классен, В.К., Борисов, И.Н., Мануйлов, В.Е. Техногенные материалы в производстве цемента: монография под общ. ред. В.К. Классена. Белгород: Изд-во БГТУ. - 2008. - 126 с.

6. Christos-Triantafyllos Galbenis, StamatisTsimas. Use of construction and demolition wastes as raw materials in cement clinker production China Particuology. 2006. - Vol. 4. - Is. 2. - P. 83 - 85.

7. Sutas, J., Mana, A., Pitak, L. Effect of rice husk and rice husk ash to properties of bricks. Procedia Engineering. - 2012, 32. - P. 1061 - 1067.

8. Prasad, C.S., Maiti, K.N., Venugopal, R. Effect of rice husk ash in whiteware compositions. Journal Ceramics International. - 2001, 27. - P. 629 - 635.

9. Свідерський, В.А., Черняк, Л.П., Сальник, В.Г., Сікорський, О.О., Дорогань, Н.О. Інструментальні методи хімічного аналізу силікатних систем. - Київ: «Політехніка». - 2017. - 172 с.

10. Пахомова, В.М., Дорогань, Н.О., Черняк, Л.П. Виготовлення та тестування композитів з різновидами мінеральних зв'язуючи і наповнювачів: лабораторний практикум. - Київ: «Політехніка». - 2019. - 68 с. 11. Свідерський, В.А., Черняк, Л.П., Дорогань, Н.О., Сорока, А.С. Програмне забезпечення технології портландцементу. Строительные материалы и изделия. - 2014. - № 1 (84). - С. 16 - 17.

12. Зозуля, П.В., Никифоров, Ю.А. Проектирование цементных заводов. - С. - Петербург: Синтез. 1994. - $444 \mathrm{c}$.

13.Николаев, В.А., Кондращуенко, Е.В. Вяжущие свойства портландцемента. Контроль и анализ. Харьков: ХНУГХ им. А.Н. Бекетова. - 2017. - 82 с. 14. ДСТУ Б В.2.7-46:2010. Будівельні матеріали. Цементи загально будівельного призначення. Технічні умови. 